\title{
The Cause of Abnormal Skin Findings after Ultrasound-Guided Injection of Cyanoacrylate Glue in an Animal Model
}

\author{
Soo Yeon Chung, Sungsin Cho, Jin Hyun Joh \\ Department of Surgery, Kyung Hee University Hospital at Gangdong, Kyung Hee University School of Medicine, Seoul, Korea
}

Received October 25, 2020 Revised November 11, 2020 Accepted November 15, 2020

\section{Correspondence to:}

Jin Hyun Joh

Department of Surgery, Kyung Hee University Hospital at Gangdong, Kyung Hee University School of

Medicine, 892 Dongnam-ro,

Gangdong-gu, Seoul 05278, Korea

Tel.: +82-2-440-6261

Fax: +82-2-440-6296

E-mail: jhjoh@khu.ac.kr
Purpose: Cyanoacrylate closure has been recently introduced as a non-thermal method for the treatment of varicose veins. An abnormal skin finding can be an extremely worrisome complication after a cyanoacrylate closure. This study aimed at identifying if joint movement could be a possible cause for this reaction using a pig model.

Methods: The pigs were administered general anesthesia and monitored by a veterinarian. After aseptic preparation, the cyanoacrylate glue was injected into the leg vein through a delivery catheter, or into the ear vein through a $22 \mathrm{G}$ needle. The pigs were divided into 2 groups according to the involvement of the joints, with the injected glue. Ten days after the glue was injected, the veins were harvested, and pathologic findings were analysed.

Results: We obtained 6 vein specimens with the surrounding tissue. Both the groups, involving the joint, and not involving the joint included one leg vein and 2 ear veins. The pathologic finding in the group not involving the joint showed that inflammatory cells (mainly lymphocytes) infiltrated the vein wall. In the group involving the joints, the same inflammatory cells infiltrated both the vein wall and surrounding tissue.

Conclusion: In this animal study, the injected glue triggered an inflammatory reaction. When the glue was injected across a joint, an inflammatory reaction developed in the vein wall as well as the surrounding tissue. It may be assumed that cyanoacrylate glue injected during closure of the vein can result in an abnormal skin finding if there is an active movement of the joint involved.

Keywords: Varicose veins, Cyanoacrylates, Inflammation, Lymphocyte, Pathology

\section{INTRODUCTION}

Cyanoacrylate closure (CAC) using the VenaSeal Closure System (Medtronic, Dublin, Ireland) as the nonthermal, nontumescent (NTNT) therapy is an accepted treatment for saphenous vein reflux. The first human feasibility trial reported a $94.7 \%$ closure rate at 12 months that remained unchanged at 36 months. $(1,2)$ The European Sapheon Closure System Observational Prospective (eSCOPE) trial showed a closure rate of $90 \%$ at 12 months.(3) The VeClose trial was a multicenter, prospective, randomized controlled trial comparing $\mathrm{CAC}$ with radiofrequency ablation (RFA) for the treatment of great saphenous vein (GSV) reflux. The target vein closure rate after CAC in the VeClose study was $97.2 \%$ at 12 months and $95.3 \%$ at 24 months, respectively. $(4,5)$

The CAC achieves occlusion of the target vein without thermal damage to the vein. Therefore, it has been associated with fewer adverse events, less postprocedural pain, and a more rapid return to normal activity than conventional thermal ablation such as RFA and endovenous laser 
therapy (EVLT).(4) However, CAC causes a local inflammatory reaction in the vein wall and surrounding tissue.(6) The inflammatory reaction was accompanied by abnormal skin findings such as erythema, itching, pain, edema, and tenderness over the treated vein area.

Until now, the exact cause of abnormal skin findings has not been reported. A recent report indicates that these abnormal skin findings occur more frequently after treatment of GSV. $(7,8)$ Anatomically, GSV crosses the knee joint and is involved in knee joint movement. Therefore, the aim of this study was to evaluate the effect of active movement on the development of abnormal skin findings after a CAC procedure.

\section{METHODS}

All animal procedures were done in accordance with our institutional guidelines for animal research. We selected the ear veins and superficial hindlimb veins of the pigs to evaluate the effect of active movement on the development of abnormal skin findings. Because the hindlimb vein crosses the hindlimb joint of a pig, it is similar to the human GSV. Ear veins were chosen due to the active movement of the pig ear, and because of the vein prominence as a result of thin skin on the ear. The Institutional Animal Care and Use Committee (IACUC) approved all experimental procedures (Approval No. MIC-IACUC-2017-01).

The pigs were administered general anesthesia and monitored by a veterinarian. The hindlimb from the mid-thigh to toe was prepped with Betadine solution. Sterile technique was observed throughout the entire procedure. Under ultrasound guidance, the superficial vein of the hindlimb was located to determine a site for access. After aseptic preparation, the cyanoacrylate glue was injected into the vein of the leg though a delivery catheter, or into the vein of the ear through a $22 \mathrm{G}$ needle. We divided the pigs into 2 groups according to the joint involvement with the injected glue. Ten days after the glue injection, the veins were harvested and pathologic findings were obtained. After selecting an access site, ultrasound guidance access was used to access the SEV with a 21-gauge needle from a 5F Micro Introducer Kit. A 0.018 In guidewire was advanced into the vein and access was confirmed with ultrasound. Then, a $7 \mathrm{~F}$ introducer sheath coupled with a $5 \mathrm{~F}$ glue-delivery catheter was inserted into the vein. With compression of the vein proximal to the tip of the catheter, two $0.1 \mathrm{ml}$ aliquots of cyanoacrylate were delivered $1 \mathrm{~cm}$ apart with additional hand compression at the treated segment for 3 minutes. Subsequent $0.1 \mathrm{ml}$ aliquots were deliv-

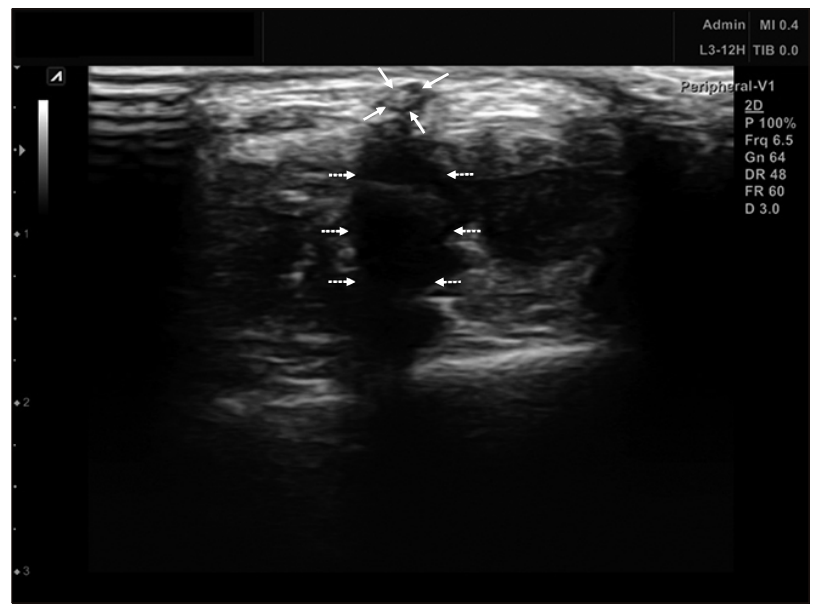

Fig. 2. After injecting the glue, ultrasound imaging confirmed the complete occlusion of vein (arrows) and acoustic shadowing below the glue (dotted arrows).
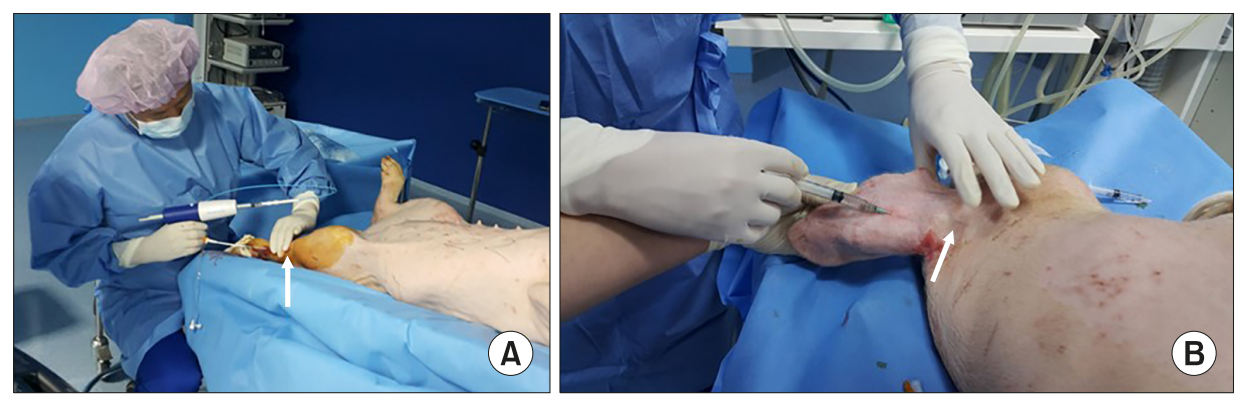

Fig. 1. Procedure details. (A) After access of superficial vein in the hindlimb, cyanoacrylate glue was injected using $5 \mathrm{~F}$ delivery catheter. (B) For the injection of glue into the ear vein, direct injection was done using $3 \mathrm{ml}$ syringe and 21-gauge angiocath. 
ered at $3 \mathrm{~cm}$ intervals along the target treatment vein and compression with the ultrasound probe and free hand was performed for 30 seconds at each treated segment. For the ear vein, we used a $3 \mathrm{ml}$ syringe and 21-gauge angiocath for injection of glue (Fig. 1). After injecting the glue and compressing the vein, ultrasound confirmed the occlusion of vein (Fig. 2).

We divided the pigs into 2 groups according to the joint involvement with the injected glue. For the joint-involvement group, glue was injected into the vein across the hindlimb joint or ear joint. We used ultrasound to confirm that the injected glue crossed the joint. For the joint non-involvement group, glue was injected with compression of the vein before the joint. Ten days after injection of glue, the veins were harvested and pathologic findings were obtained.

\section{RESULTS}

We investigated the injection sites to evaluate the occurrence of abnormal skin changes 10 days after glue injection. In one ear vein from the joint-involvement group, abnormal skin change was observed. Along the glue-injected vein, er- ythematous change was observed (Fig. 3).

We obtained 6 vein specimens including surrounding tissue (2 leg veins and 4 ear veins). Microscopic findings showed complete occlusion of venous lumen. The lumen was filled with a mixture of glue and red blood cells. Lymphocytic infiltration was observed throughout the vein wall. The pathologic findings in the joint non-involvement group showed that the inflammatory cells, mainly lymphocytes, infiltrated the vein wall. In the joint involvement group, the same inflammatory cells infiltrated the vein wall as well as surrounding tissue (Fig. 4).

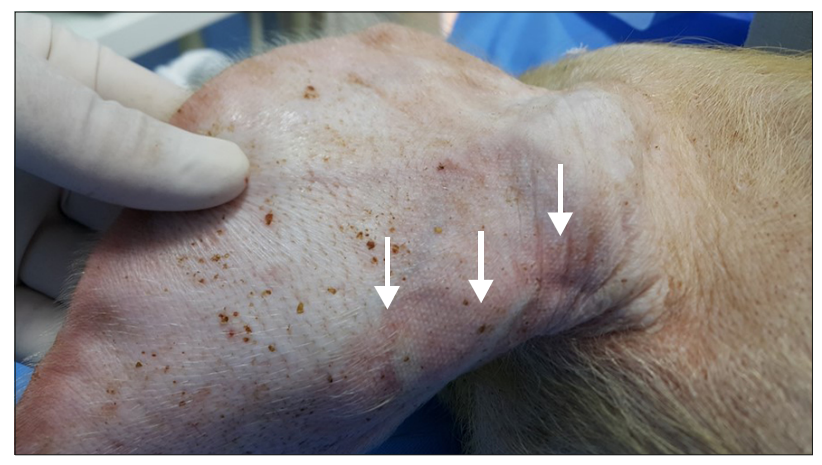

Fig. 3. Typical feature of abnormal skin change in joint-involvement group. Along the vein injected glue, erythematous change was observed (arrows).

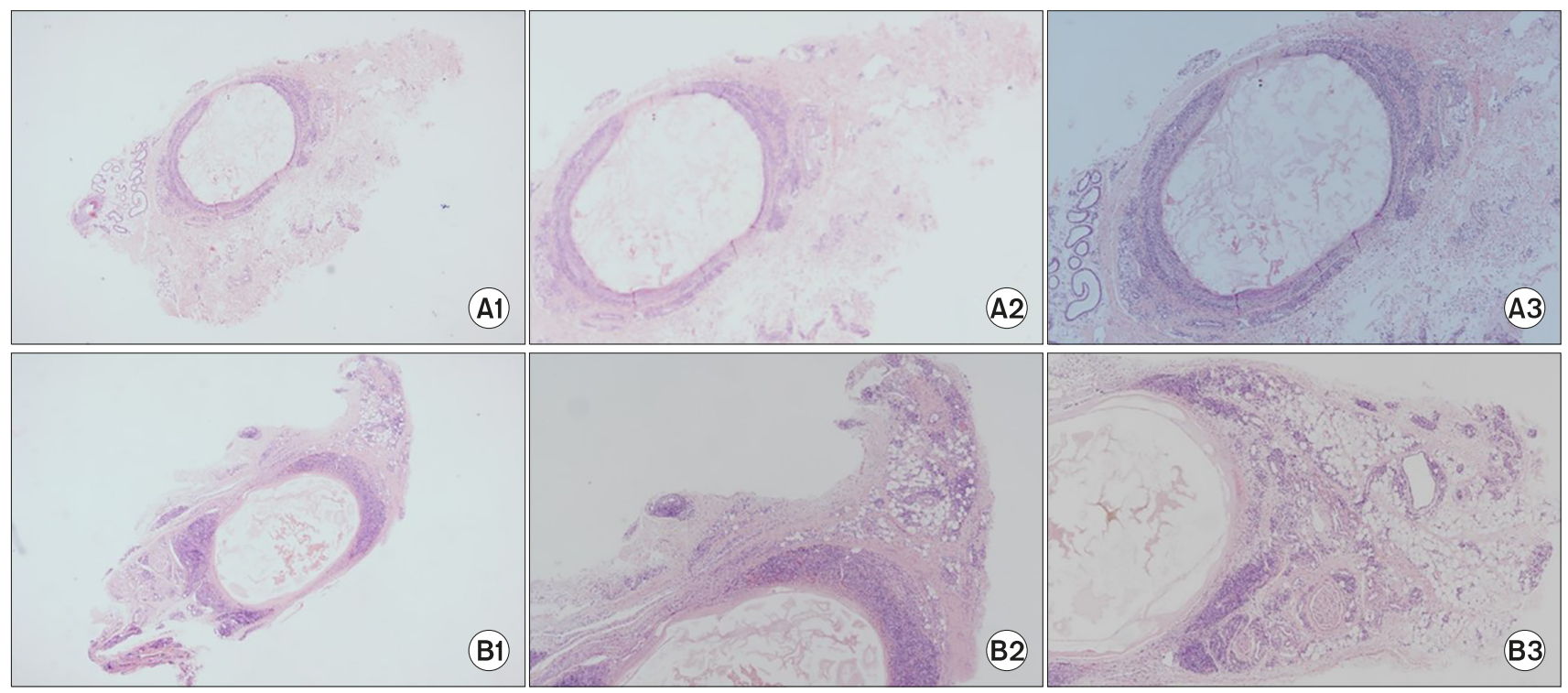

Fig. 4. Pathologic finding. The lymphocyte infiltration was seen mainly within the vein wall $(\mathrm{A} 1,2,3)$ in the joint non-involvement group. But, in the joint involvement group, the lymphocytic infiltration was seen both in vein wall and surrounding tissue (B1, 2, 3). 


\section{DISCUSSION}

Microscopic examination confirmed the presence of cyanoacrylate in the lumen of the vessels with deposition of thrombus. The occlusion of venous lumen was achieved by the injection of glue and thrombus instead of the coaptation of vein wall. Inflammation of varying intensity was observed throughout the glue-injected veins. Inflammatory changes were confined to the vein wall in the area without active movement. However, these changes were seen in the vein walls as well as the perivascular soft tissues with active movement.

When cyanoacrylate glue contacts anionic substances within the body such as blood cells, endothelium, or plasma, the adhesive begins to polymerize.(9) This process caused the treated veins to become completely occluded. Min et al.(6) revealed histological findings that the lumen was dilated by coalescing, arborizing clear spaces with entrapped lytic erythrocytes. Microscopic images in our study demonstrated the same findings.

This polymerization damages the vascular intima, induces immunological responses, and triggers an acute inflammatory reaction in the wall. $(10,11)$ Inflammation is a complex process of the body's response to foreign materials. In the acute phase, cells of the immune system migrate to the site of exposure of foreign materials in a carefully orchestrated sequence of events that is mediated

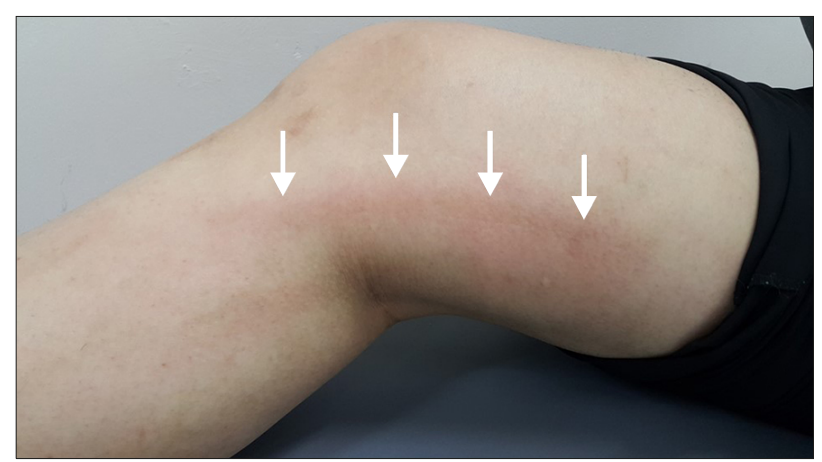

Fig. 5. Typical finding of the patient with phlebitis reaction after cyanoacrylate closure. The inflammatory change such as erythema, pain, and induration was seen along the course of treated saphenous vein (arrows). by cytokines and acute phase proteins.(12) Persistent inflammation as a result of prolonged exposure to foreign materials can lead to the chronic phase. In chronic inflammation, the primary immune cells are macrophages and T lymphocytes.(13) The microscopic image showed the accumulation of lymphocytes within the veins and surrounding tissue in response to the cyanoacrylate.

Physical stimuli are an important cause of inflammation.(14) The combined stimuli of cyanoacrylate and physical movement can exaggerate the inflammation process. Therefore, an inflammation reaction can develop within the vein as well as the surrounding tissue. Typically, the phlebitis-like reaction after cyanoacrylate closure for saphenous vein insufficiency can develop along the treated vein (Fig. 5).

The most common complication of $\mathrm{CAC}$ is an abnormal skin findings, reported at a rate of $11.4 \%-20 \% .(15,16)$ This abnormal skin findings clinically presented with erythema, edema, pruritus, and tenderness, and was unresponsive to non-steroidal anti-inflammatory drugs (NSAID). It was suggested as a type IV delayed hypersensitivity reaction due to a foreign material, rather than localized inflammation, and was alleviated by antihistamines and steroids in over $85 \%$ of patients. (7) Type IV hypersensitivity, also known as delayed-type hypersensitivity, is a T-cell mediated immune response. Microscopic findings in our study demonstrated that most of the cells accumulated within the vein and surrounding tissue were lymphocytes.

After approximately one month, the response progresses to a granulomatous process with foreign body giant cells and fibrosis. $(17,18)$ Novotny et al.(19) reported a histopathological examination of vein samples from six patients who had undergone great saphenous vein sealing with Histoacryl and Lipiodol to treat chronic venous insufficiency of the superficial venous system. Histologic findings showed that the lumen of the dilated vessel was filled with granulation tissue with a pronounced giant cell reaction centered on the non-staining foreign material. However, Jones et al.(8) obtained the vein specimen from the patient with persistent hypersensitivity reaction at 200 
days after treatment. Immunohistochemical stain showed that most of the mononuclear cells were $\mathrm{T}$ lymphocytes, and most of these were of the T4 subset.

In conclusion, injected glue initiated an inflammatory reaction. If glue was injected across the joint, the inflammatory reaction developed in the vein wall as well as the surrounding tissue. It may be assumed that the injected glue on active movement can be a cause of abnormal skin findings after cyanoacrylate closure.

\section{CONFLICTS OF INTEREST}

None.

\section{ACKNOWLEDGMENTS}

This animal study was performed by the support of 'Covidien Center for Innovation'.

\section{REFERENCES}

1. Almeida JI, Javier JJ, Mackay E, Bautista C, Proebstle TM. First human use of cyanoacrylate adhesive for treatment of saphenous vein incompetence. J Vasc Surg Venous Lymphat Disord 2013;1:174-80.

2. Almeida JI, Javier JJ, Mackay EG, BautistaC, Cher DJ, Proebstle TM. Thirty-sixth-month follow-up of first-in-human use of cyanoacrylate adhesive for treatment of saphenous vein incompetence. J Vasc Surg Venous Lymphat Disord 2017;5: 658-66.

3. Proebstle TM, Alm J, Dimitri S, Rasmussen L, Whiteley M, Lawson J, et al. The European multicenter cohort study on cyanoacrylate embolization of refluxing great saphenous veins. J Vasc Surg Venous Lymphat Disord 2015;3:2-7.

4. Morrison N, Gibson K, Vasquez M, Weiss R, Cher D, Madsen $\mathrm{M}$, et al. VeClose trial 12-month outcomes of cyanoacrylate closure versus radiofrequency ablation for incompetent great saphenous veins. J Vasc Surg Venous Lymphat Disord 2017; 5:321-30.

5. Gibson K, Morrison N, Kolluri R, Vasquez M, Weiss R, Cher D, et al. Twenty-four month results from a randomized trial of cyanoacrylate closure versus radiofrequency ablation for the treatment of incompetent great saphenous veins. J Vasc Surg Venous Lymphat Disord 2018;6:606-13.

6. Min RJ, Almeida JI, McLean DJ, Madsen M, Raabe R. Novel vein closure procedure using a proprietary cyanoacrylate adhesive: 30-day swine model results. Phlebology 2012;27:398-403.

7. Park I, Jeong MH, Park CJ, Park WI, Park DW, Joh JH. Clinical features and management of "Phlebitis-like abnormal reaction" after cyanoacrylate closure for the treatment of incompetent saphenous veins. Ann Vasc Surg 2019;55:239-45.

8. Jones AD, Boyle EM, Woltjer R, Jundt JP, Williams AN. Persistent type IV hypersensitivity after cyanoacrylate closure of the great saphenous vein. J Vasc Surg Cases Innov Tech 20195:372-4.

9. Lam YL, De Maeseneer M, Lawson J, De Borst GJ, Boersma D. Expert review on the VenaSeal ${ }^{\circledR}$ system for endovenous cyano-acrylate adhesive ablation of incompetent saphenous trunks in patients with varicose veins. Expert Rev Med Devices 2017; 14:755-62.

10. Levrier O, Mekkaoui C, Rolland PH, Murphy K, Cabrol P, Moulin G, et al. Efficacy and low vascular toxicity ofembolization with radical versus anionic polymerization of $\mathrm{n}-\mathrm{bu}-$ tyl-2-cyanoacrylate (NBCA). An experimental study in the swine. J Neuroradiol 2003;30:95-102.

11. Pollak JS, White RI Jr. The use of cyanoacrylate adhesives in peripheral embolization. J Vasc Interv Radiol 2001;12:907-13.

12. Germolec DR, Shipkowski KA, Frawley RP, Evans E. Markers of inflammation. Methods Mol Biol 2018;1803:57-79.

13. Sakai Y, Kobayashi M. Lymphocyte 'homing' and chronic inflammation. Pathol Int 201565:344-54.

14. Germolec DR, Frawley RP, Evans E. Markers of inflammation. Methods Mol Biol 2010;598:53-73.

15. Almeida JI, Javier JJ, Mackay EG, Bautista C, Cher DJ, Proebstle TM. Two-year follow-up of first human use of cyanoacrylate adhesive for treatment of saphenous vein incompetence. Phlebology 2015;30:397-404.

16. Morrison N, Gibson K, McEnroe S, Goldman M, King T, Weiss $\mathrm{R}$, et al. Randomized trial comparing cyanoacrylate embolization andradiofrequency ablation for incompetent great saphenous veins (VeClose). J Vasc Surg 2015;61:985-94.

17. Vinters HV, Galil KA, Lundie MJ, Kaufmann JC. The histotoxicity of cyanoacrylates. A selective review. Neuroradiology 1985;27:279-91.

18. Spiegel SM, Viñuela F, Goldwasser JM, Fox AJ, Pelz DM. Adjusting the polymerization time of isobutyl-2 cyanoacrylate. AJNR Am J Neuroradiol 1986;7:109-12.

19. Novotny K, Campr V. Histopathological changes to the vascular wall after treatment of great saphenous veins using n-butyl-2-cyanoacrylate. Vasa 2019;48:399-404. 